\title{
Space- and ground-based non-accelerated long lifetime data for ruggedized commercial Non-Planar Ring Oscillator (NPRO) lasers
}

C.G. Asbury, L.I. Dorsky, N.M. Nerheim, S. Forouhar, D.M. Rider, E.Y. Chu,

B.M. Fisher, R.S. Valencia, M.R. Montero,

Jet Propulsion Laboratory, California Institute of Technology

and T.J. Kane, Unaffiliated

International Conference on Space Optics 2018

Chania, Greece

October 9, 2018 


\section{Tropospheric Emission Spectrometer (TES) \\ Laser Head and Laser Head Assembly}

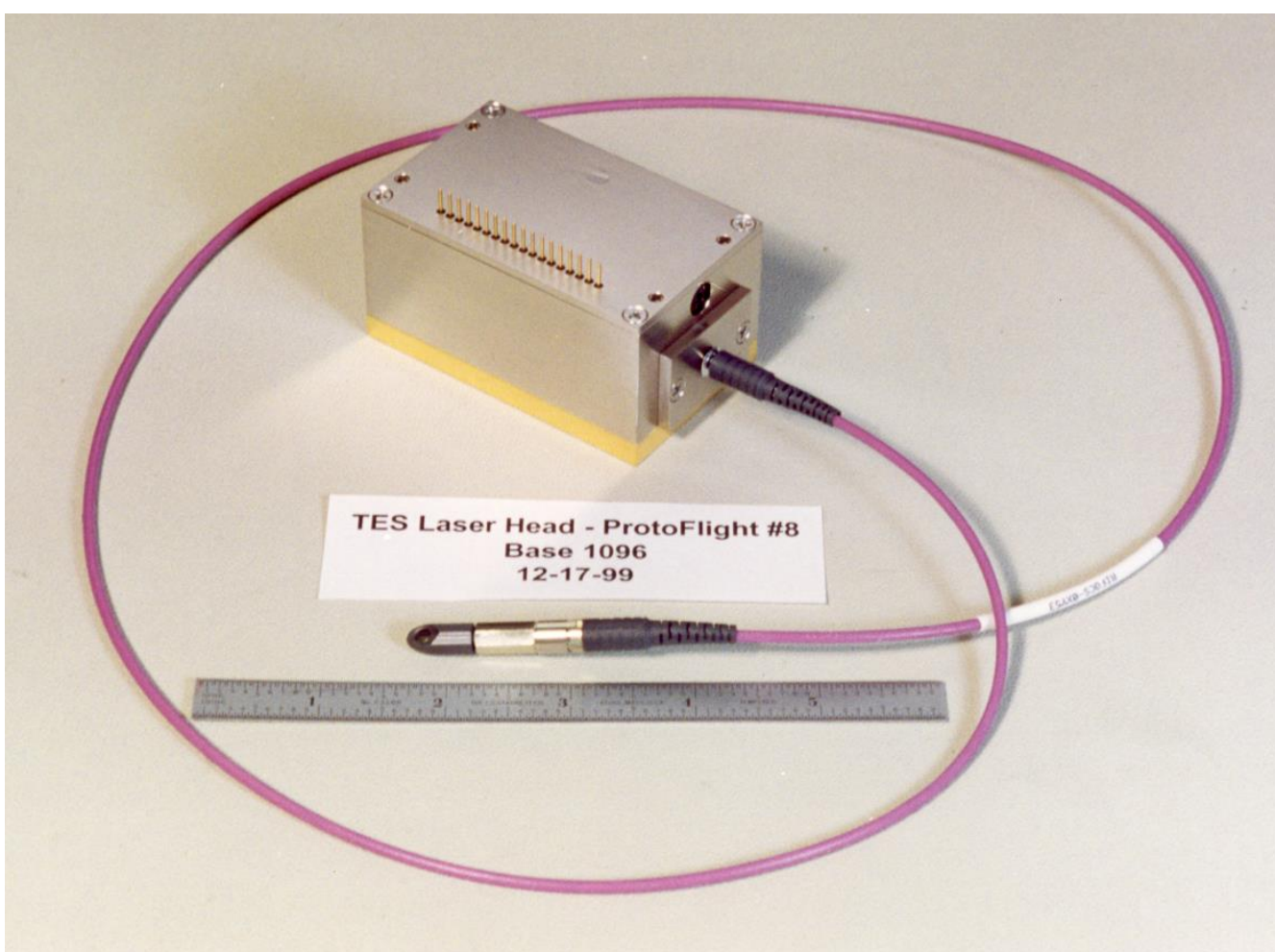

Laser B Laser Head or "Gold Box"

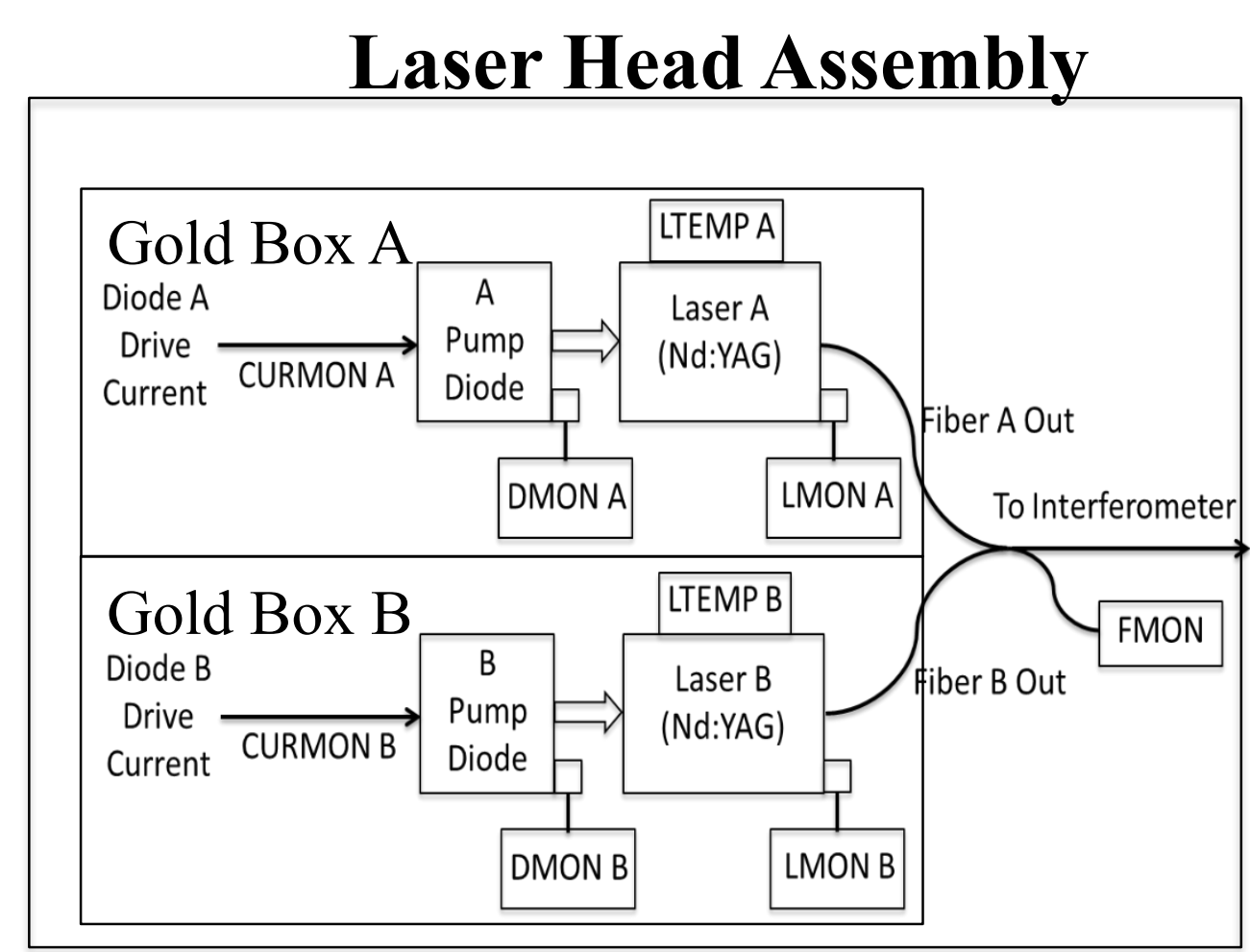

Laser Head Assembly diagram: both laser heads, 2x2 fiber coupler, \& detectors (DMONs, LMONs and FMON) 


\section{Background - TES Laser Overview}

- The TES lasers trigger sampling of the interferograms from the TES Fourier transform interferometer:

- Narrow linewidth $(\leq 2.5 \mathrm{kHz})$

- Diode laser-pumped Nd:YAG, Non-Planar Ring Oscillator (NPRO)

- $1064 \mathrm{~nm}, \geq 25 \mathrm{~mW}$ output from optical fiber pigtail

- Ruggedized version of commercial model 125 laser from Lightwave Electronics Corporation (LWE)

- 2 Brassboard lasers built

- DMON monitors the pump laser diode output power

- LMON monitors the YAG laser output just before fiber coupling

- FMON monitors the YAG laser output through the fiber pigtail

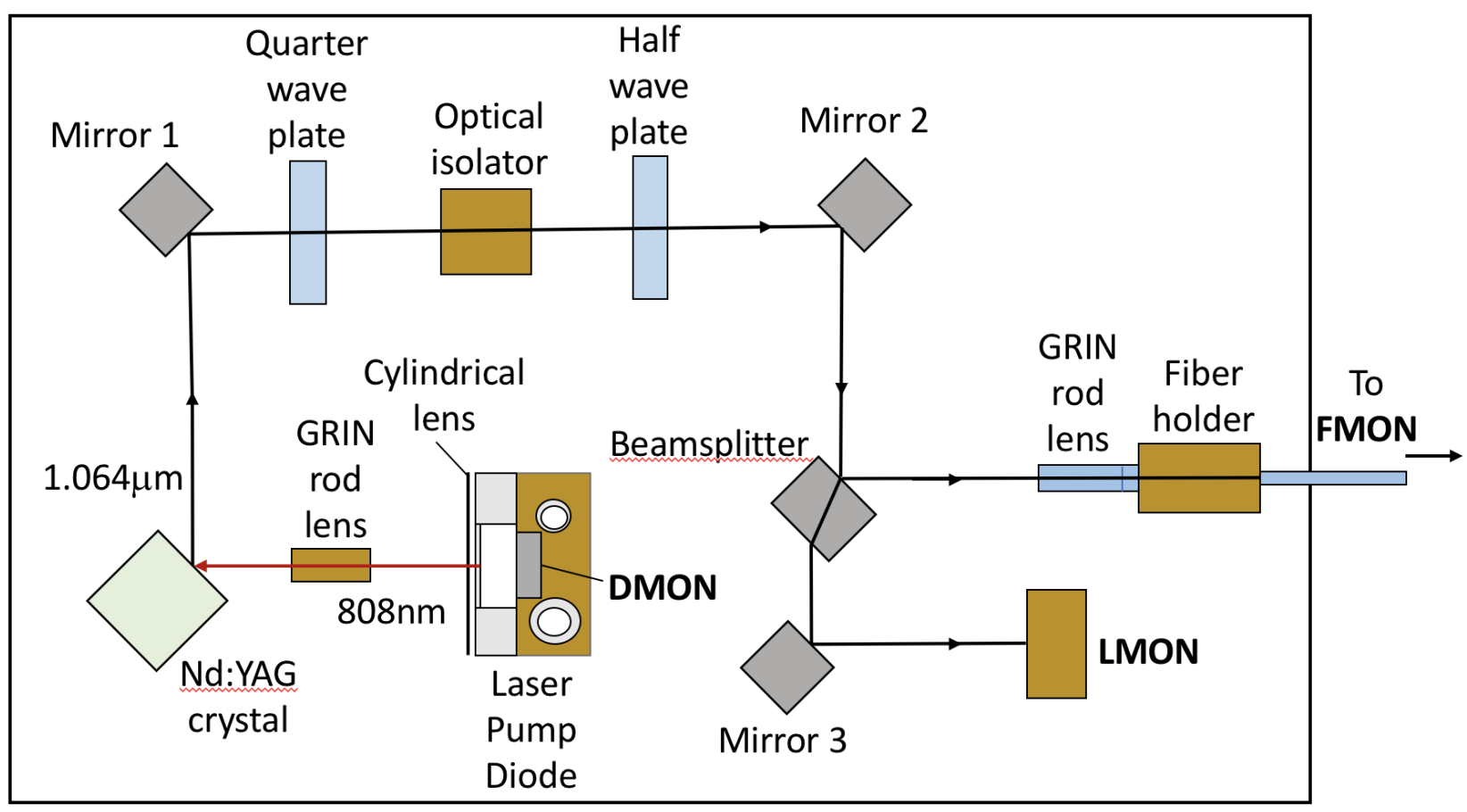




\section{Background and History of TES Lasers (con't)}

- Ruggedization of the commercial LWE 125 lasers for TES:

TECs:

- $100 \%$ visual inspection

- Measure AC resistance

\section{Pump to NPRO:}

- Re-designed mechanical mount for laser diode

- Used high Tg epoxy to mount NPRO crystal to carrier

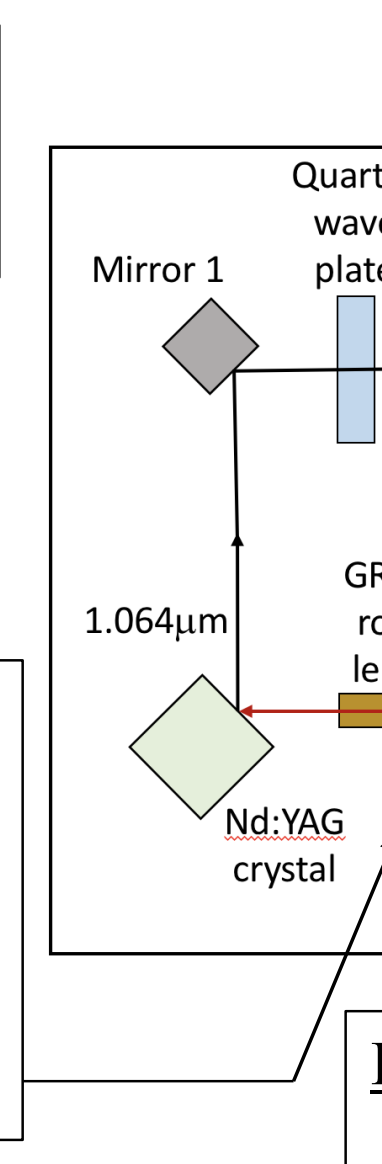




\section{Testing of Pump Laser Diodes}

1 year, 50C, 1.27 A sDL-2360-C Lifetest for Lightwave Electronics

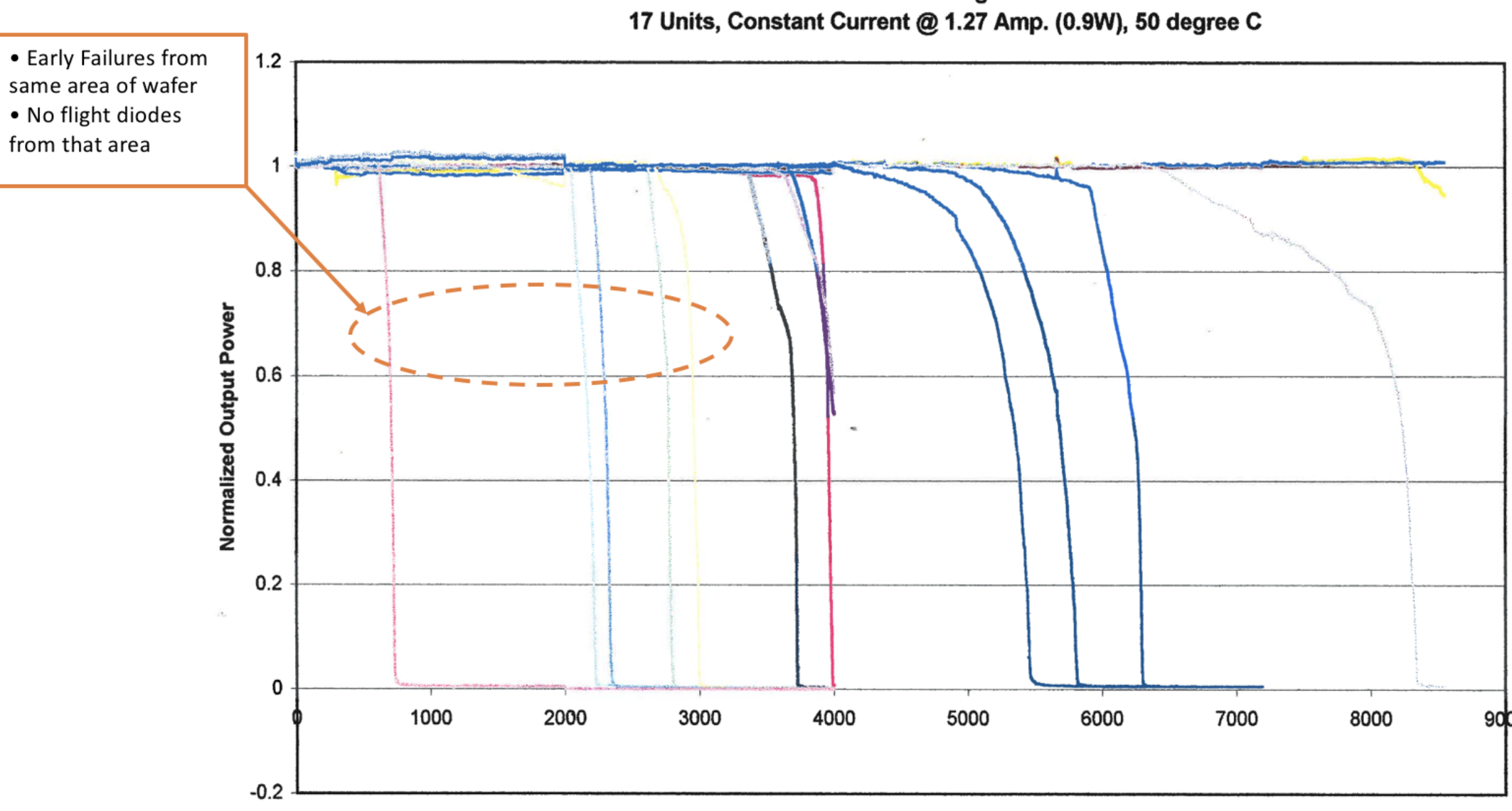

Elapsed Time (hours)
SDL Lifetime estimate:

- Wearout: 9-69 years

(Ea range is $0.5-0.8 \mathrm{eV}$,

range of $n$ is 1 to 2)

- Random: 113 years

$(\mathrm{Ea}=0.54 \mathrm{eV} ; \mathrm{n}=2.93)$

JPL lifetime estimate: 27 years

Estimates do not include early failures 


\section{Testing of Multi-stage Laser System}
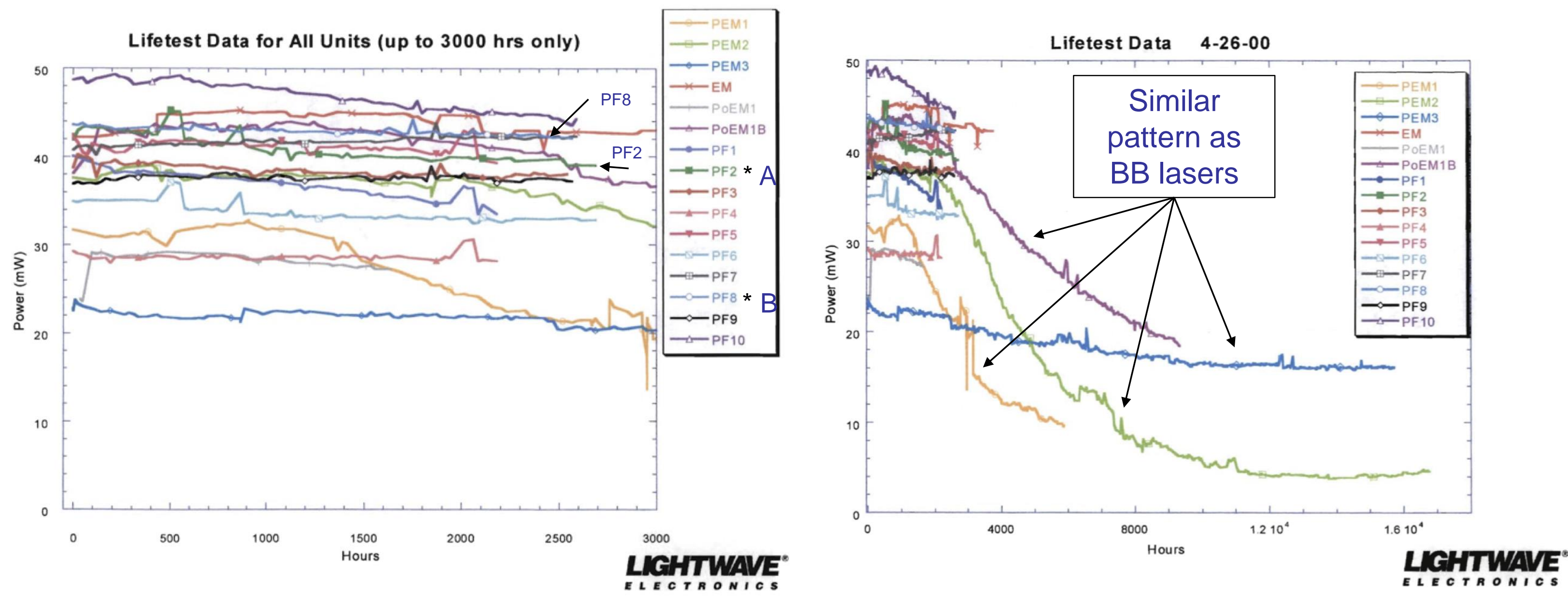


\section{Brassboard \#1 Laser Lifetime Data}

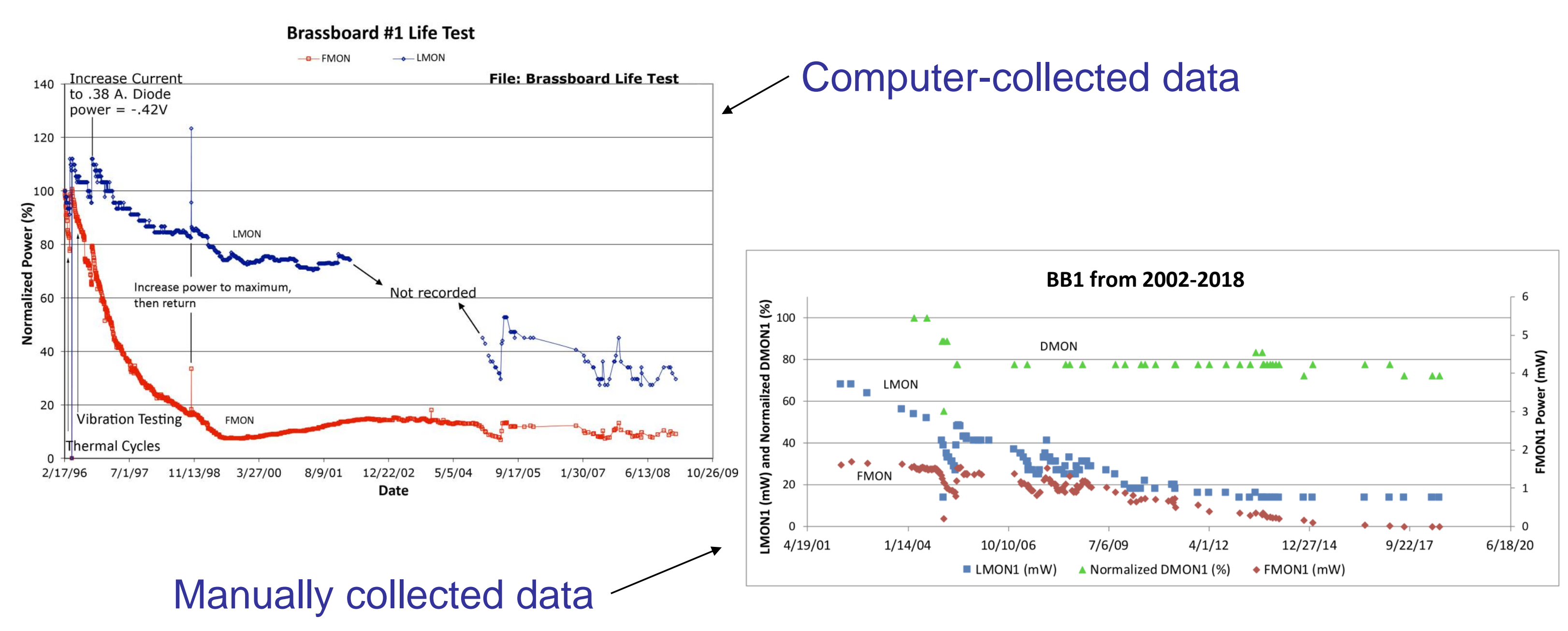




\section{Brassboard \#2 Laser Lifetime Data}

\section{BrassBoard \#2}

Initial Power: $\mathbf{3 0} \mathrm{mW}$

Start: 12/18/96

$\multimap$ LMON $\quad \longrightarrow$ FMON

File: Brassboard Life

Diode power has remained constant at $-0.37 \mathrm{~V}$ at a diode current of 0.78 since start of test

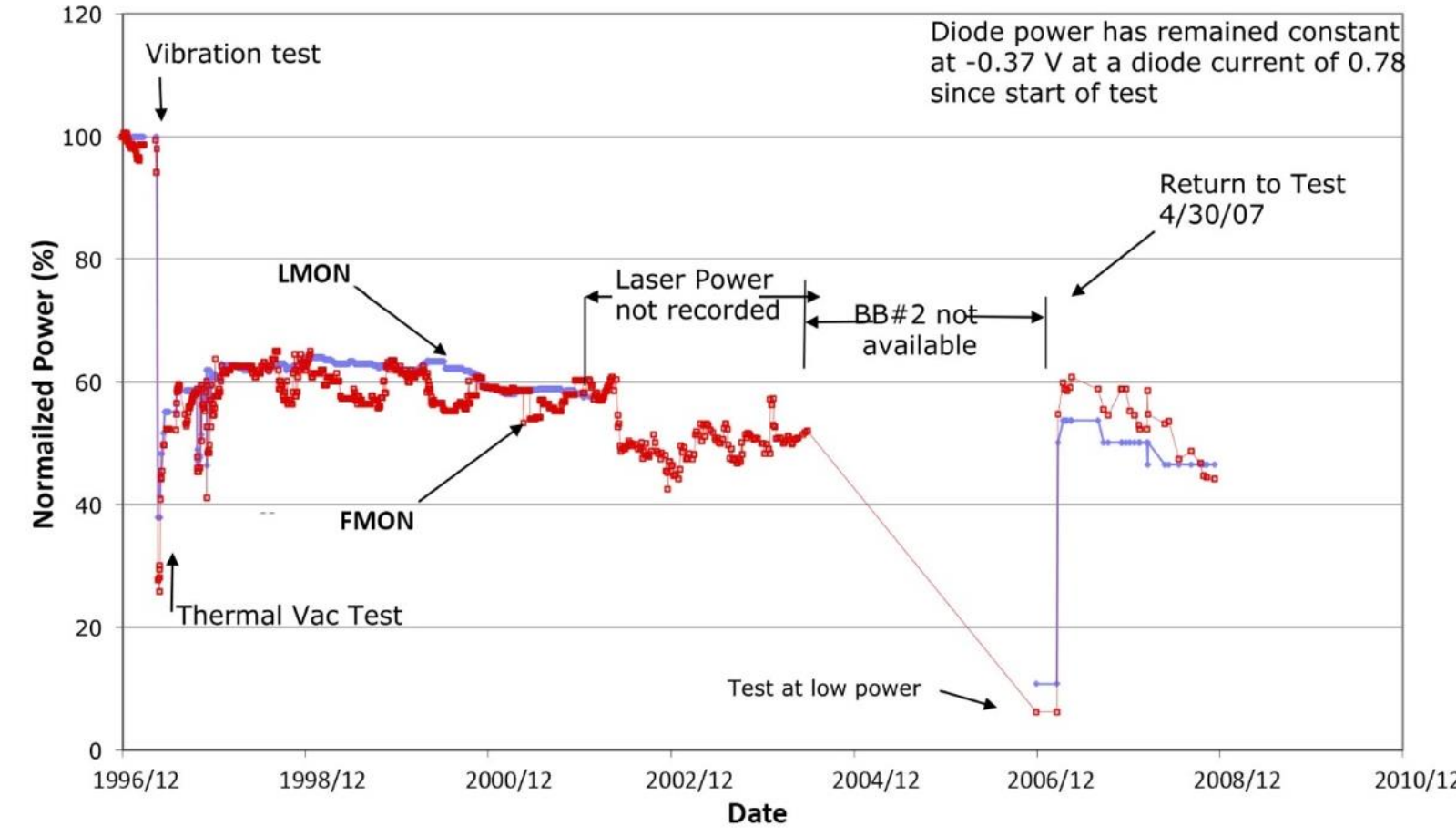

Manually collected data
Computer-collected data

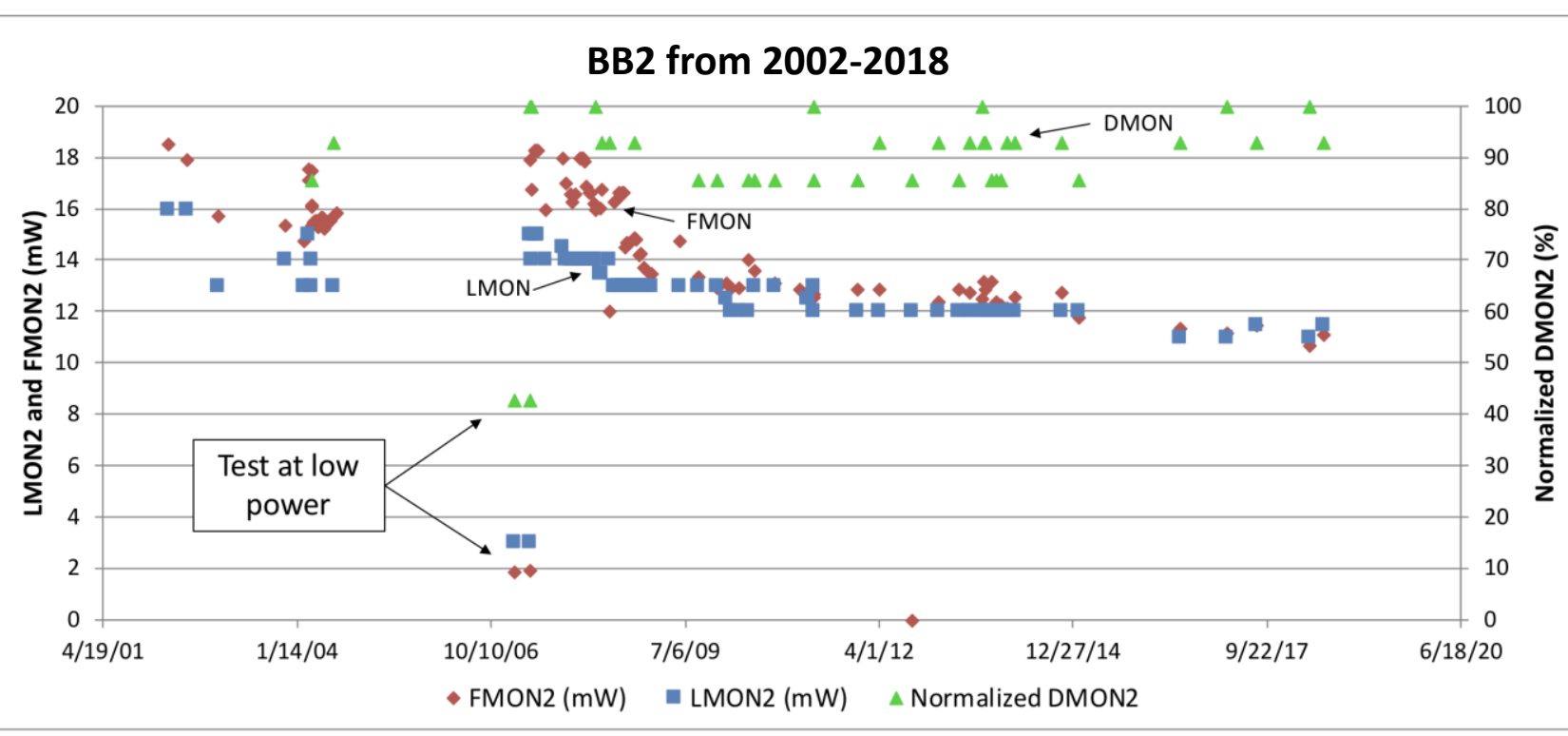




\section{Flight Laser A Life Data}

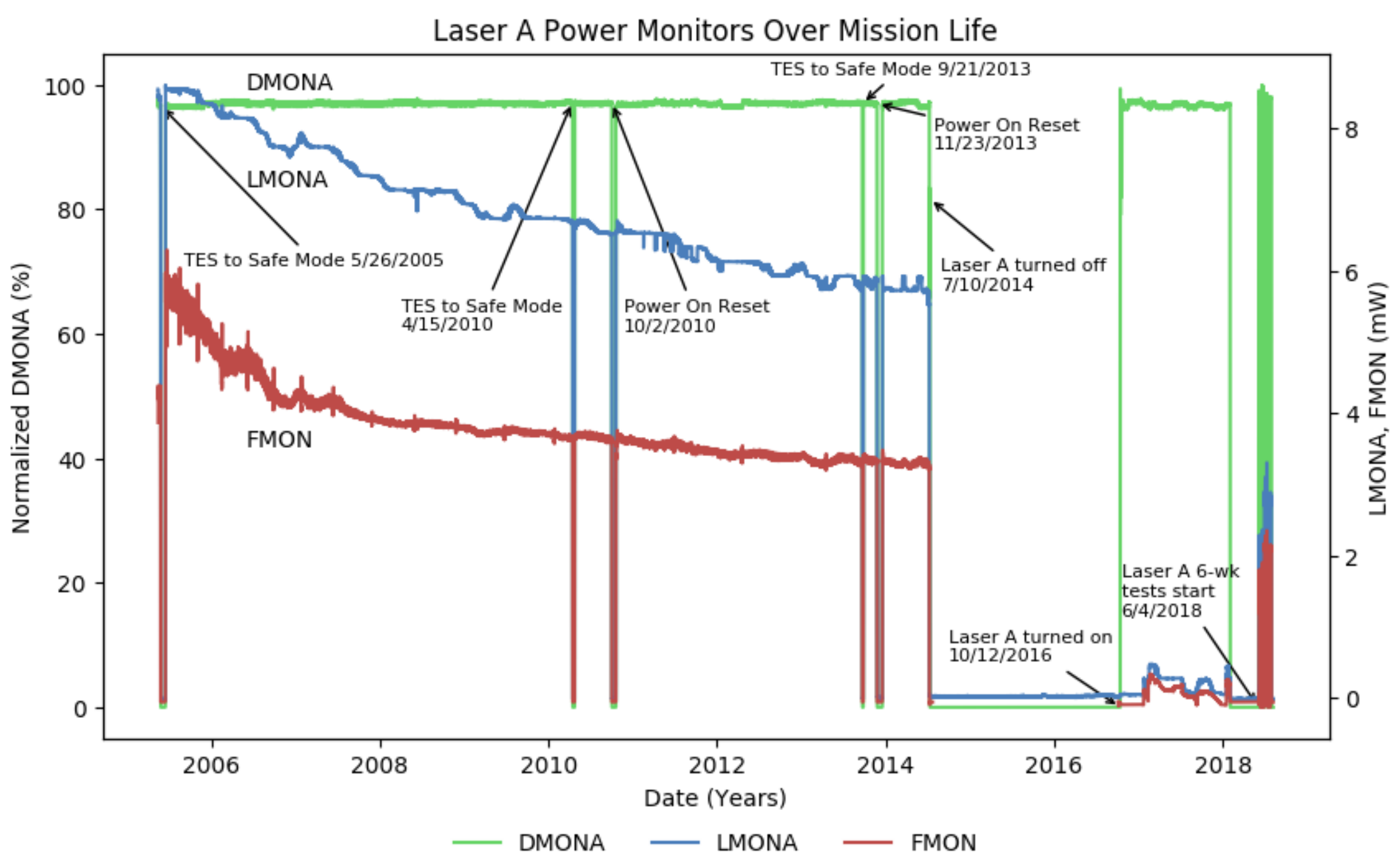




\section{Flight Laser B Life Data}

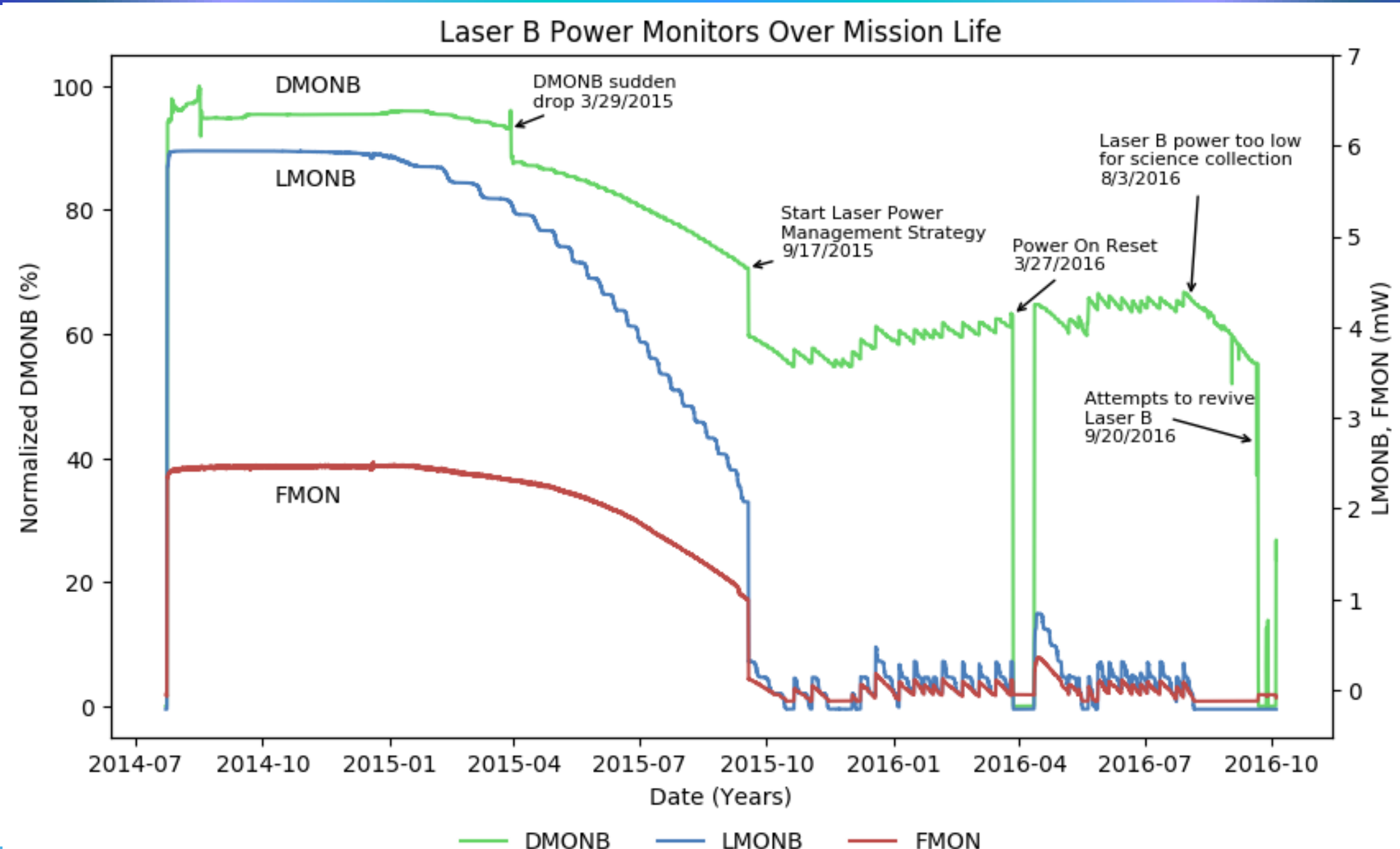




\section{Pump Diode Laser Lifetime: Predicted vs. Observed}

\begin{tabular}{|l|c}
\hline Pump laser diode: & Observed Lifetime (yrs) - Mission Criteria \\
\hline Flight Laser A & $11+$ \\
\hline Flight Laser B & 2.2 \\
\hline Brassboard \#1 & $22.5+$ \\
\hline Brassboard \#2 & $21.75+$ \\
\hline Accelerated Life Test Estimate: & 27 years \\
\hline (80\% Power Criteria) &
\end{tabular}

- Was it defective to begin with?

- Did 10 years as a cold spare in space affect it? 


\section{Multi-stage Model 125 Laser: Ground vs. Space}

- Brassboard lasers are still producing enough output to collect science data after 20+ years

- Pump laser diode output is stable for both lasers

- BB\#1 and BB\#2 show declines with patterns consistent with mechanical misalignment

- Flight Laser A was still producing enough output to collect science data at the end of the mission, but a sharp decline in LMON and FMON output was observed after 10 years that cannot be explained by misalignment of either the post-NPRO optical train or fiber coupling

- Something about the space environment may have negatively affected Laser A output

- Pump laser diode wavelength shift due to aging in space?

- lonizing radiation affecting the NPRO?

- Flight Laser B no longer produced enough power for science collection 2.2 years after initial turn-on in space after 10 years as a cold spare 


\section{Summary}

- Data from non-accelerated life tests of LWE Model 125 lasers was presented from:

- Over 20 years of on-going ground-based life tests

- 14 years of space-based laser operations

- Flight Laser A successfully enabled TES Instrument science data collection for more than $2 X$ the required mission life of 5 years (and more than $4 X$ the required laser life)

- This real-time long life data has provided the opportunity to compare:

- Real-time pump laser diode lifetime measurements with accelerated life test estimates

- Lifetime on the ground vs. lifetime in space of a complex, multi-stage hybrid laser system

- Lifetime data from 3 different power monitor points in the optical train were collected:

- Analysis of the differences in trends over time among the 3 power monitors could provide insight into the failure mechanisms of observed degradations as the lasers age. 